\title{
Status of TRMM Monthly Estimates of Tropical Precipitation
}

\author{
Robert F. Adler \\ Laboratory for Atmospheres \\ NASA Goddard Space Flight Center \\ Greenbelt, MD \\ Christian Kummerow \\ Dept. of Atmospheric Sciences \\ Colorado State University \\ Fort Collins, $\mathrm{CO}$ \\ David Bolvin \\ Science Systems and Applications, Inc. \\ Lanham, MD \\ Scott Curtis \\ Joint Center for Earth-System Technology \\ Baltimore, MD \\ Chris Kidd \\ University of Birmingham \\ Birmingham, U.K.
}

Submitted to Meteorological Monographs

Symposium on Cloud Systems, Hurricanes and TRMM

October, 2000

Corresponding author address: Robert F. Adler

Mail Code 912

Goddard Space Flight Center

Greenbelt, MD 20771

Phone: 301-614-6290

e-mail: Robert.Adler@gsfc.nasa.gov 


\title{
Status of TRMM Monthly Estimates of Tropical Precipitation
}

\begin{abstract}
Nearly three years of TRMM monthly estimates of tropical surface rainfall are analyzed to document and understand the differences among the TRMM-based estimates and how these differences relate to the pre-TRMM estimates and current operational analyses. Variation among the TRMM estimates is shown to be considerably smaller than among a pre-TRMM collection of passive microwave-based products. Use of both passive and active microwave techniques in TRMM should lead to increased confidence in converged estimates.
\end{abstract}

Current TRMM estimates are shown to have a range of about $20 \%$ for the tropical ocean as a whole, with variations in heavily raining ocean areas of the ITCZ and SPCZ having differences over $30 \%$. In mid-latitude ocean areas the differences are smaller. Over land there is a distinct difference between the tropics and mid-latitude with a reversal between some of the products as to which tends to be relatively high or low. Comparsions of TRMM estimates with ocean atoll and land gauge information point to products that might have significant regional biases. The radar-based product is significantly low biased compared with atoll raingauge data, while the passive microwave product is significantly high compared to raingauge data in the deep tropics. 
The evolution of rainfall patterns during the recent change from intense El Niño to a long period of La Niña and then a gradual return to near neutral conditions is described using TRMM. The time history of integrated rainfall over the tropical oceans (and land) during this period differs among the passive and active microwave TRMM estimates. 


\section{Introduction}

The Tropical Rainfall Measuring Mission (TRMM), a joint satellite mission of the United States and Japan, was launched in late November 1997 and is providing a wealth of information related to precipitation in the tropics. A description of the mission and the satellite instruments, along with a summary of initial results from the mission is given by Kummerow et al. (2000) and by Simpson et al. (2000). This paper examines the estimates of tropical surface precipitation made by TRMM and compares these results to those of the pre-TRMM era and the monthly global analyses of the Global Precipitation Climatology Project (GPCP) (Huffman et al., 1997).

When the concept of a TRMM-like mission was first proposed in the early to mid-1980's (the first TRMM Science Working Group Meeting was in 1986) there was little quantitative knowledge of the magnitude and geographic and seasonal distribution of rainfall in the tropics, especially over the oceans. Climatologies based on ship reports of weather (e.g., Jaeger, 1976; Legates and Wilmott, 1990) described the oceanic Intertropical Convergence Zone(ITCZ) and other features, but differed considerably on the magnitude of tropical rainfall and exactly how it was distributed over the tropical oceans, even in terms of a long-term climatology. Satellite-based estimates during the 
period 1975-1985 focused on use of both infrared (IR) satellite data (especially geosynchronous data) and on data from the early passive microwave instruments. Cloud statistics from geosynchronous IR obsevations were compared to GATE surface-based radar data (Arkin and Meisner, 1987) to produce a simple relation that when applied to geosynchronous data from around the globe gave rainfall estimates that allowed seasonal and interannual changes to be described. The Electrically Scanning Microwave Radiometer (ESMR), flying on the Nimbus 5 polar-orbiting satellite launched in 1974, measured upwelling radiation at $19 \mathrm{GHz}$, enabling estimates of precipitation to be made (Wilheit et al., 1977). A later Nimbus instrument, the Scanning Multi-channel Microwave Radiometer (SMMR), provided multi-frequency observations up to $37 \mathrm{GHz}$ and was also used to estimate precipitation. However, over-water precipitation measurements from both of these instruments were limited in accuracy because of data quality, instrument calibration and sampling issues.

In mid-1987 the first in a series of Special Sensor Microwave/Imager (SSM/I) instruments (Hollinger et al. 1990) was launched on board a U.S. Department of Defense polar orbiting satellite. This well calibrated, conically-scanning instrument observing frequencies between 19 and $86 \mathrm{GHz}$ provided operational agencies and researchers the observational basis for developing and applying passive microwave precipitation algorithms.

TRMM built on the hardware and science experience provided by results from these SSM/I instruments. TRMM combined a SSM/I like instrument, with an additional 
frequency at $10 \mathrm{GHz}$ (TRMM Microwave Imager[TMI]), with an active microwave sensor at $14 \mathrm{GHz}$ (Japan's Precipitation Radar[PR]). These two instruments, combined with a lower orbit altitude for higher spatial resolution and a precessing orbit to observe the diurnal cycle, provide the most complete precipitation-observing complement of instruments ever sent into orbit. Two additional instruments complete TRMM's precipitation package. The Visible Infrared Scanner (VIRS) provides the connection from precipitation observations to cloud information available from high time resolution (hourly) geosynchronous observations. The Lightning Imaging Sensor (LIS) provides lightning occurrence information critical in determining lightning-precipitation relations and microphysical insights. The TRMM instruments are described in Kummerow et al. (1998).

TRMM was launched late in November, 1997 and has completed nearly three years of data taking. This paper will asses these three years of TRMM surface precipitation estimates, how they compare with the pre-TRMM state of precipitation estimation, and how they compare with a standard research analysis of monthly precipitation.

1. Tropical precipitation estimates at the time of TRMM launch

At the time of TRMM's launch in late 1997 there was still considerable variation in the estimation of rainfall over the tropical oceans. Fig. 1 shows a collection of zonal averaged rainfall over ocean for the year 1992 based on SSM/I microwave data and various algorithms submitted for an algorithm intercomparison exercise in 1996 called 
PIP-3 (Third Precipitation Intercomparison Project) (see Adler et al., 2000b). Obviously, the estimated values vary considerably. At the peak at $8^{\circ} \mathrm{N}$ the values range from 120 to $260 \mathrm{~mm} / \mathrm{month}$, a factor of more than two. In the subtropic minima the range of values remains approximately a factor of two and increases to over a factor of three at $40^{\circ}$ latitude in both hemispheres. An even larger range of values results when all the PIP-3 observational products (including IR-based and others) are included.

The collection of passive microwave estimates in Fig. 1 is a good representation of the broad state of knowledge of tropical oceanic rainfall in the middle 1990's. In the following section the TRMM-based estimates resulting from both the TMI (passive microwave) and PR (active microwave) instruments are compared to the pre-TRMM results of Fig. 1.

\section{Climatological rainfall from TRMM}

A summary of TRMM rain products discussed in this paper is presented in Table 1. The Levels $(2$, or 3 ) follow the standard NASA nomenclature. Level 2 consists of the retrieved geophysical parameters at the satellite footprint level, while level 3 products represent either space or time averaged geophysical parameters. All rainfall products discussed here are Version 5, introduced on Oct. 1, 1999. Details on the algorithms can be found in the references in Table 1 . 
Maps of TRMM climatologies from January 1998 to August 2000 [3 FULL YEARS SHOULD BE AVAILABLE FOR PUBLICATION] are shown in Fig. 2 for each of the satellite products resulting from application of the algorithms (Version 5) at a spatial resolution of $2.5^{\circ}$ latitude and longitude, except for the TMI Statistical product which is only available at $5^{\circ}$ resolution over ocean. The patterns are very similar, with the differences in magnitude to be discussed shortly. Portions of the Inter-Tropical Convergence Zone (ITCZ) are evident in both hemispheres over the Atlantic and Pacific Oceans, along with land maxima in Africa, South America and over the maritime continent. Mid-latitude maxima are evident across and to the east of Japan and the United States.

An intercomparison of zonal mean rainfall accumulations for 1998-2000 for the five major rainfall algorithms (Version 5) is presented in Fig. 3. Version 5 of the algorithms represents the initial improvements of the algorithms during the first two years after launch, beyond corrections made to eliminate software errors. As can be seen from Fig 3, the zonal averages for this near three year period have a wide range between the TMI profiling algorithm and the that of the PR. Table 2 gives the ocean, land and total precipitation in the $37.5^{\circ} \mathrm{N}-37.5^{\circ} \mathrm{S}$ band for each of the TRMM products and also includes the estimate based on the GPCP monthly analyses. The tropical mean estimates (ocean only) vary from $92 \mathrm{~mm} /$ month for the TMI (2A-12) to $75 \mathrm{~mm} / \mathrm{month}$ for the PR (2A-25) estimate, a range of $17 \mathrm{~mm} /$ month or $20 \%$. This is the same approximate range of values shown by Kummerow et al. (2000), using a period of one year (1998). The land values also have a similar value of range (20\%). The TRMM Version 5 results do 
indicate a significant narrowing of the differences among the algorithms as compared to the earlier Version 4 (Kummerow et al. 2000). The GPCP value over the oceans is the same as that from TRMM 3A-11, which is not surprising because a very similar algorithm applied to SSM/I data is the driver for the combination of data over the oceans for the operational GPCP analyses. The GPCP analyses include raingauge information over land so therefore gives a first indication of possible biases of the TRMM satellite products over land.

Table 1: TRMM Satellite Products

\begin{tabular}{|lll|}
\hline Name & Ref. no. & Purpose \\
\hline $\begin{array}{l}\text { Level 2 data } \\
\text { TMI profiles }\end{array}$ & 2A12 & $\begin{array}{l}\text { Sfc. rainfall and 3-D structure of hydrometeor } \\
\text { and heating over TMI swath. } \\
\text { (Kummerow, et al. 1996) }\end{array}$ \\
PR profiles & 2A-25 & $\begin{array}{l}\text { Sfc rainfall and 3-D structure of hydrometeors } \\
\text { over PR swath } \\
\text { (Iguchi et al., 1998) }\end{array}$ \\
$\begin{array}{lll}\text { PR/TMI Combined } \\
\text { Level 3 data }\end{array}$ & 2B31 & $\begin{array}{l}\text { Sfc. rainfall and 3-D structure of hydrometeors } \\
\text { derived from TMI and PR simultaneously }\end{array}$ \\
(Haddad et al., 1997)
\end{tabular}


Table 2. Tropical Rainfall Totals

\begin{tabular}{|l|c|c|c|}
\hline \multicolumn{1}{l}{ Ocean } & Land & Total \\
TMI-profiling & $92 \mathrm{~mm} / \mathrm{mo}$ & $107 \mathrm{~mm} / \mathrm{mo}$ & $96 \mathrm{~mm} / \mathrm{mo}$ \\
\hline $\begin{array}{l}\text { PR } \\
\text { 2A-25 }\end{array}$ & 75 & 76 & 78 \\
\hline $\begin{array}{l}\text { PR-TMI } \\
\text { 2B-31 }\end{array}$ & 80 & 99 & 85 \\
\hline $\begin{array}{l}\text { TMI-Stat } \\
\text { 3A-11 }\end{array}$ & 88 & -- & -- \\
\hline $\begin{array}{l}\text { TRMM/Other } \\
\text { Satellites } \\
\text { 3B-42 }\end{array}$ & 83 & 98 & 87 \\
\hline \begin{tabular}{l} 
GPCP \\
\hline
\end{tabular} & & 84 & 87 \\
\hline
\end{tabular}

To obtain a feeling of how this variation among the TRMM-based estimates relates to the pre-TRMM spread, the standard deviation of the eighteen SSM/I-based estimates over ocean from PIP-3 in Fig. 1 is compared to the same statistic from the collection of four TRMM estimates, also over the ocean. The product which includes the geostationary observations was not included in this exercise in order to keep it an all-microwave 
comparison. The result in Fig. 4 shows that the variation among the TRMM microwave products is significantly smaller than from the earlier collection of SSM/I-based products. These results can be interpreted as TRMM making a significant improvement in the estimation of total rainfall in the tropics as compared to the wide range of estimates available before TRMM, although it should be noted that some of the estimates in Fig. 1 were considered experimental. Perhaps more importantly it should also be remembered that the two TRMM products which use the PR information had no previous application to satellite data and therefore are at an earlier stage of testing with space data as compared to the passive microwave algorithms which have had extensive testing with SSM/I data.

The fact that at this point in analysis of TRMM data there is still a fairly significant difference in magnitude among the TRMM products is not that surprising considering the variability of the pre-TRMM products and the "youth" of the PR-related algorithms. Because the passive microwave and radar estimates depend in very different ways on the microphysics and structure of the rainfall, their eventual convergence should strengthen our confidence in the resulting estimates.

3. Time evolution of TRMM estimates.

During the first three years of TRMM, the patterns in tropical precipitation underwent a significant change. A rapid transition from El Niño to La Niña rainfall patterns occurred during the first half of 1998 (Adler et al.., 2000a), followed by a long period of La Niña 
pattern into the middle of 2000 and then a return to a near neutral ENSO status. This evolution during the three year TRMM data set can be see in Fig. 5, where anomalies from monthly precipitation climatologies are shown. The TRMM 3B-43 product is used for this figure, although each of the products would show qualitatively similar evolutions. The monthly climatologies used are based on the GPCP 20-year climatology, adjusted to match the magnitude of the 3B-43 product over the three year period. The top panel in Fig. 5 shows the anomalies in January 1998, near the beginning of the TRMM mission and when the El Niño was still very strong. A very large excess in rainfall is obvious in the eastern Pacific Ocean along with a rainfall deficit extending from the Indian Ocean, through the Maritime Continent and into the western North Pacific Ocean. A significant area of above average of rain is evident in East Africa and also a general deficit of rain over the Amazon. The negative anomaly along the north side of the Pacific Ocean maximum is related to the ending of the El Niño.

The second panel of Fig. 5 shows the situation a year later, in January 1999. The anomaly pattern is strikingly different at this point with above average rainfall over the Maritime Continent and a rainfall deficit over the central Pacific Ocean. The transition from El Niño to La Niña occurred very rapidly in early 1998 as can be seen in Fig. 6 which shows the evolution of the ENSO Precipitation Index (ESPI) [Curtis and Adler, 2000] and the Nino 3.4 SST anomalies and Southern Oscillation Index (SOI) during the TRMM mission. The ESPI is a measure of the strength of the anomalous Walker circulation based on gradients of the precipitation anomalies over the Maritime Continent and the central Pacific Ocean. The ESPI, and the other indices, show a rapid change 
from strong positive (El Niño) to strong negative (La Niña) during the first half of 1998. Thus the first year of TRMM encompassed the end of a major El Niño and the first part of a La Niña.

The La Niña continued throughout 1999 (see Fig. 6) and the anomaly map for January 2000 (third panel in Fig. 5) shows a pattern very similar to that of January 1999. By July 2000 (bottom panel of Fig. 5) the La Niña had weakened and the anomaly pattern had smaller scale features over the Indian and Pacific oceans. The indices in Fig. 6 were nearing neutral conditions. Thus TRMM viewed La Niña conditions for about two years between mid-1998 and mid-2000.

Although all the TRMM products show the same pattern of anomaly fields during the 1998-2000 period, there is a difference in the evolution of the tropical total rainfall during the 1998-2000 period. Fig. 7 shows the time change of the TRMM estimates integrated over water and over ocean plus land. The top panel (Fig. 7a) is an extension in time of a figure in Adler et al. (2000a), here using Version 5 data. The results confirm that, over ocean, the TRMM passive microwave product (2A-12) shows a decrease from the El Niño still in progress in early 1998 into the period of the extensive La Niña through 1999 and into 2000. However, the two products which use the TRMM radar data have nearly constant ocean totals over the three years (only $2 \mathrm{~A}-25$ is shown). When land is included to produce a total tropical rainfall, the decrease from 1998 to 1999 in the passive product is muted. This difference in trends among the TRMM products may be related to regional differences in the accuracy of the different TRMM estimates and the 
shift of the location of the rainfall maxima in the transition from El Niño to La Niña during the first year of TRMM. Fig. 8 displays the matched probability density function (pdf) values of one passive microwave algorithm (2A-12) versus the radar algorithm (2A25) for monthly values for the 1998 and 1999 months of January, February and March. One can see that in both years the passive-based estimates exceed the radar estimates above very low values. However, there is a distinct difference in the magnitude with 1998, the El Niño year, having much higher $2 \mathrm{~A}-12$ relative values. The difference between the years is small at values below about $150 \mathrm{~mm} / \mathrm{month}$, but increases drastically at higher values. Thus the difference between these two estimates as a function of time in Fig. 7 a seems to be related to differences in the estimates in the heaviest raining areas. Even though this analysis is based on monthly values, high rainfall amounts on a monthly scale are typically related to occurrences of large convective systems with large instantaneous rainfall rates and large stratiform regions. These type of systems need to be investigated to determine how the algorithms perform in these situations.

4. Regional variations among TRMM products

To examine the variations among the TRMM algorithms on a regional basis a mean of the four TRMM-alone products for the 2.5 years of data was made and maps of the deviation from that mean were done for each product (Fig. 9). Remember that there are only three products over land. In the deep tropics over ocean, in the areas of rainfall maxima (e.g., ITCZ and SPCZ), the algorithms give similar relative results. The passive profiling algorithm (2A-12) is highest with the radar-only algorithm $(2 \mathrm{~A}-25)$ and the 
passive statistical (3A-11) having the lowest values and the combined radar-radiometer algorithm (2B-31) in between. The passive-statistical product (3A-11) has narrow bands of less than the mean values exactly in the peak areas along the ITCZ, with above average values just outside the maximum rain areas. This pattern is due partially to the five degree latitude-longitude areas in which the product is computed, but may also reflect a difference in areas of very heavy rain between estimating rain on a pixel basis as in the profiling algorithm and on a distribution-fitting basis as in the statistical technique. The ratio of values between $2 \mathrm{~A}-12$ and $2 \mathrm{~A}-25$ is over 1.3 in these areas of heavy climatological rainfall over the ocean.

In the rain maxima of mid-latitudes over oceans the differences among the estimates is somewhat muted. The passive profiling algorithm is generally still the largest, but the difference between it and the radar product is smaller ratio-wise, about 1.1 to 1.2. The combined product is somewhat lower than the radar-only product in these areas. However, there are some interesting regional differences in the relative magnitudes among the products above $30^{\circ}$ latitude. In the Northern Hemisphere the radar product (2A-25) is nearly the same as the profiling product in the North Atlantic, unlike the situation east of Japan in the North Pacific. In the Southern Hemisphere similar differences are noted with the most dramatic being off the southeast coast of Australia where $2 \mathrm{~A}-25$ is significantly larger than $2 \mathrm{~A}-12$.

In the subtropical minima over the oceans things are somewhat reversed, with the radar (2A-25) being slightly higher than the passive profiling product (2A-12). The passive 
statistical (3A-11) estimates are the highest and this translates to this product being highest in the latitudinal profiles of Fig. 2, both in the subtropics and at mid-latitudes.

Thus, over oceans, there are some generalities as to the relative magnitudes of the four products, but there is significant variation regionally.

Over land there are also large differences among the algorithms as is clear in Figs. 3 and 9. Over the tropical land maxima of Africa and the Amazon (Fig. 9), the TMI profiling algorithm is the highest, the radar-based estimate the lowest and the combined algorithm has intermediate values. The difference between $2 \mathrm{~A}-12$ and $2 \mathrm{~A}-25$ is about $30 \%$ over the Amazon and nearly 50\% over Africa. The combined product (2B-31) is above the three product mean in the high rain areas of the Amazon, but lower than the mean over similar areas of Africa. In mid-latitudes over land, e.g., in southeast China or the southern U.S., the combined product (2B-31) is highest, the TMI product the lowest and the radar only product is intermediate in value. The differences in mid-latitude are relatively small, however, about $10-15 \%$. Therefore, there are significant regional differences in the relative biases of the TRMM products, with the primary variation related to latitude.

5. Comparison with ground-based estimates

Comparison of monthly surface rainfall estimated from TRMM with ground-based estimates from gauges and from radar-gauge merged data sets can be valuable to help diagnose the large-scale and regional differences among the TRMM estimates and 
possibly point to algorithm improvement strategies. However, because the ground-based data sets do not cover all regions (especially over the ocean) and have their own measurement errors it is not always easy to draw concrete conclusions. Fig. 10 shows results of comparing the TRMM products and the GPCP analysis for the last three years with the monthly estimates from the Western Pacific Ocean atoll raingauge data set (Morrissey et al., 1991). Although the scatter of points is large, due to both the sampling errors of TRMM and those of the sparse gauge coverage, the results indicate that the monthly estimates have a wide range in the calculated bias between the satellite and the gauge estimate. The TMI (2A-12) algorithm has an overall small negative bias (-1\%) [Fig. 10a]. The monthly estimates based on the PR (2A-25) algorithm [Fig. 10b] show a much larger bias (-31\%). Surprisingly, the TMI-statistical product (3A-11) has a large, negative bias, especially in the high rain areas. The similar algorithm applied to SSM/I data does not have the same large bias. The GPCP plot (Fig. 10f) gives an indication of that since that algorithm drives the combination product for the GPCP analysis. The combined radar-radiometer product (2B-31) and the product that uses $2 \mathrm{~B}-31$ to adjust the geosynchronous data (3B-42) have intermediate, negative biases. These comparisons indicate that at least in the heavily raining area of the Western Pacific Ocean the passive profiling and combination products are closer to the mean values estimated from gauges and that the radar and passive-statistical products appear low compared to the gaugebased estimates.

Comparisons of the TRMM estimates with a gauge-based analysis (Rudolf et al., 1994) $\left(2.5^{\circ}\right.$ latitude/longitude boxes) was used to diagnose some of the regional differences 
seen in the algorithms over land. Figs. 11 and 12 show results of the satellite-gauge comparison for locations inside and outside of $15^{\circ}$ latitude. The results indicate that, in the deep tropics over land, the TMI profiling algorithm has a much larger positive bias $(+29 \%)$ than the PR algorithm ( $+3 \%)$ (Fig. 11). Outside of $15^{\circ}$ latitude the biases are the same and moderately positive $(+11 \%)$ (Fig. 12). These results point to the need for evaluation of the passive microwave algorithm over land to understand the regional variation.

In summary, comparison of TRMM results with existing gauge analyses over land and water indicate that, over water, the more mature TMI profile product compares well with atoll-based rain gauges, while the more experimental PR algorithm produces estimates significantly lower than the atoll gauges in the Western Pacific Ocean, as does the TMIstatistical product. Over land comparison of TRMM products with gauge analyses produce reasonable results with relatively small biases outside of $15^{\circ}$ latitude, but the TMI-based product has large positive biases relative to the gauges in the deep tropics.

\section{Conclusions}

With nearly three full years of data the Tropical Rainfall Measuring Mission (TRMM) is making a considerable contribution to our knowledge of climatological rainfall over the tropics. The large range of possibilities with regard to absolute values that existed in the pre-TRMM era has been reduced, even though the TRMM estimates include those incorporating space-borne radar data for the first time. Because the TRMM passive 
microwave and radar estimates depend in different ways on the microphysics and structure of the rainfall, their eventual convergence should strengthen our confidence in the resulting estimates. However, at this relatively early stage of the TRMM research effort the TRMM estimates still differ among themselves and those differences vary regionally.

With nearly three years of data the TRMM estimates are shown to have a range of about $20 \%$ for the tropical ocean as a whole. Similar differences exist over land. The TRMM estimates vary around an ensemble mean of $84 \mathrm{~mm} /$ month $(2.8 \mathrm{~mm} / \mathrm{d})$ over the tropical ocean, $97 \mathrm{~mm} /$ month $(3.2 \mathrm{~mm} / \mathrm{d})$ over the land and $88 \mathrm{~mm} / \mathrm{month}(2.9 \mathrm{~mm} / \mathrm{d})$ combined. Regional variations among the algorithms are noted in maps and zonal averages with differences in heavily raining ocean areas of the ITCZ and SPCZ having differences over $30 \%$. In mid-latitude ocean areas the differences are smaller. Over land there is a distinct difference between the tropics and mid-latitude with a reversal between some of the products as to which tends to be relatively high or low. Surface-based comparison data indicates that in the deep tropics the radar algorithm may be underestimating over the ocean, whereas the passive product may be overestimating over land.

TRMM began its flight during an intense El Niño and there was a rapid transition to a La Niña during 1998. The evolution of this ENSO event can be followed with the TRMM đáta in terms of movement of precipitation anomalies as is typically seen with these events. However, when the precipitation is integrated over the tropical oceans (and land) the time variation of these quantities is not the same depending on whether one is using 
the active or passive microwave products from TRMM. This difference in trend is, at least, partially related to the divergence of estimates in the very heavy raining areas.

The differing TRMM estimates of surface rainfall noted in this paper should converge when the physical basis for the algorithm differences are understood. Resolving these differences among the TRMM estimates and producing improved, converged estimates of tropical climatological rainfall remain among TRMM's highest scientific priorities.

\section{References}

Adler, R.F., G.J. Huffman, D.T. Bolvin, S.Curtis, E.J. Nelkin, 2000a: Tropical Rainfall Distributions Determined Using TRMM Combined with Other Satellite and Raingauge Information, J. Appl. Meteor., (In press).

Adler, R. F., C. Kidd, G. Petty, M. Morrissey, H. Goodman, 2000b. Intercomparison of Global Precipitation Products: The Third Precipitation Intercomparison Project (PIP-3), Bull. Amer Met. Soc., (submitted)

Arkin, P. A. and B. N. Meisner, 1987: The relationship between large-scale convective rainfall and cold cloud over the Western Hemisphere during 1982-1984. Mon. Wea. Rev., 115, pp. 51-74.

Chang, A.T.C., L. S. Chiu, C. Kummerow, and J. Meng, 1999: First Results of the TRMM Microwave Imager (TMI) Monthly Oceanic Rain Rate: Comparison with SSM/I. Geophys. Res. Letters, 26, 2379-2382.

Curtis, S., and R. Adler, 2000: ENSO indices based on patterns of satellite derived precipitation. J. Climate, 13, 2786-2793.

Curtis, S., R. Adler, G. Huffman, D. Bolvin, and E. Nelkin, 2000: Global precipitation during the 1997-98 El Niño and initiation of the 1998-99 La Niña. Int. J. Clim. (submitted).

Haddad, Z. S., E.A.Smith, C.D.Kummerow, T.Iguchi, M.R.Farrar, S.L.Durden, M.Alves and W.S.Olson, 1997: The TRMM "Day-1" radar/radiometer combined rain-profiling algorithm. J. Met. Soc. Japan 75 (4), 799-809. 
Hollinger, J. P., J. L. Pierce, and G. A. Poe, 1990: SSM/ Instrument Evaluation. Trans. IEEE Geosci and Remote Sens., 4, 781-790.

Huffman, G.J., R.F. Adler, P. Arkin, A. Chang, R. Ferraro, A. Gruber, J. Janowiak, A. McNab, B. Rudolf, U. Schneider, 1997: The Global Precipitation Climatology Project (GPCP) Version 1 Data Set. Bull. Amer. Meteor. Soc., 78, 5-20.

Iguchi, T., Kozu, T., Meneghini, R., Awaka, J. and Okamoto, K., 1998: Preliminary results of rain profiling with the TRMM precipitation radar. Proc. $8^{\text {th }}$ URSI Com F Triennial Open Symposium. "Wave Propagation and Remote Sensing", Aveiro Portugal, $147-150$.

Jaeger, L., 1976: Monatskarten des Niederschlags fur die ganze Erde. Ber. Dtsch. Wetterdienstes, 139, 33pp.

Kummerow, C., W.S. Olson, and L. Giglio, 1996: A simplified scheme for obtaining precipitation and vertical hydrometer profiles from passive microwave sensors. IEEE Trans. Geosci. Remote Sens., 34, 1213-1232.

Kummerow, C., W. Barnes, T. Kozu, J. Shiue, and J. Simpson, 1998: The Tropical Rainfall Measuring Mission (TRMM) Sensor Package. J. Atmos. and Ocean Tech.., 15, 808-816.

Kummerow, C., J. Simpson, O. Thiele, W. Barnes, A.T.C. Chang, E. Stocker, R.F. Adler, A. T.C. Chang, E. Stocker, R.F. Adler, A. Hou, R. Kakar, F. Wentz, P. Ashcroft, T.

Kozu, Y. Hong, K. Okamoto, T. Iguchi, H. Kuroiwa, E. Im, Z. Haddad, G. Huffman, T. Krishnamurti, B. Ferrier, W.S. Olson, E. Zipser, E.A. Smith, T.T. Wilheit, G. North and K. Nakamura. "The Status of the Tropical Rainfall Measuring Mission (TRMM) after 2 Years in Orbit". 2000. J. Appl. Meteor. (In press).

Legates, D., and C. J. Willmott, 1990: Mean seasonal and spatial variability in gaugecorrected, global precipitation. Int. J. Climatol., 10, 111-127.

Rudolf, B., H. Hauschild, W. Rueth and U. Schneider (1994): Terrestrial Precipitation Analysis: Operational Method And Required Density Of Point Measurements. In: Global Precipitations and Climate Change (Ed. M. Desbois, F. Desalmond), NATO ASI Series I, Springer-Verlag, 26, pp. $173-186$.

Simpson, J., C. Kummerow, W.-K. Tao and R. F. Adler, 1996: "On the Tropical Rainfall Measuring Mission (TRMM)," Meteorol. and Atm. Phys., 60, 19-36.

Simpson, J., C. Kummerow, R. Meneghini, A. Hou, R. Adler, G. Huffman, B. Barkstrom, B. Wielicki, St. Goodman, H. Christian, T. Kozu, T. Krishnamurti, S. Yang and B. Ferrier, 2000. The Tropical Rainfall Measuring Mission (TRMM) Progress Report. Studying the Earth from Space, 2, 
Wilheit, T. T., T. C. Chang, M.S. V. Rao, E. B. Rodgers and J.S. Theon, 1977: A satellite technique for quantitatively mapping rainfall rates over the oceans. J. Appl. Meteor., 16, 551-560.

\section{FIGURE CAPTIONS:}

Fig. 1. Zonally-averaged, latitudinal profiles of oceanic precipitation for 1992 for 18 algorithms using SSM/I passive microwave data submitted for the PIP-3 algorithm intercomparison activity.

Fig. 2. Maps of mean precipitation during the period January, 1998 to August 2000 from five TRMM products.

Fig. 3. Zonally-averaged, latitudinal profiles of oceanic and land precipitation from five TRMM products (four over land) for the period January, 1998 to August 2000.

Fig. 4. Standard deviation as a function of latitude among monthly rainfall estimates. Three of the curves are for the standard deviation during the three years of TRMM among the four TRMM ocean estimates. The PIP-3 curve is for the standard deviation among the 18 estimates seen in Fig. 1.

Fig. 5. Evolution of rainfall anomaly fields during 1998-2000 based on the TRMM merged analysis product (3B-43).

Fig. 6. Evolution of ENSO indices during the 1998-2000 period. The three indices are the ENSO Precipitation Index of Curtis and Adler (2000), the Nino 3.4 Sea Surface Temperature (SST) anomaly, and the Southern Oscillation Index (SOI).

Fig.7. Evolution of integrated rainfall over ocean, land and total area during the period 1998-2000 from two TRMM estimates and the GPCP analysis.

Fig. 8. Plots of matched probability density function (PDF) values of rain estimates over the tropical ocean using the TMI profiling (2A-12) and radar (2A-25) algorithms for January, February and March of 1998 (El Nino) and 1999 (La Nina).

Fig. 9. The mean map of rainfall using the average of four TRMM algorithms (three over land) for the period January 1998 and August 2000 (top panel) and the difference from that mean for each of the four algorithms (the lower four panels).

Fig. 10. Comparison of TRMM (and GPCP) monthly estimates with Pacific atoll gauges. The analysis is done for $2.5^{\circ}$ latitude-longitude boxes with at least one gauge. 
Fig. 11. Comparison of TRMM monthly estimates with raingauge analyses over the latitude band $15^{\circ} \mathrm{N}$ to $15^{\circ} \mathrm{S}$. The analysis is done for $2.5^{\circ}$ latitude-longitude boxes with at least two gauges.

Fig. 12. Comparison of TRMM monthly estimates with raingauge analyses over the latitude band poleward of $15^{\circ}$ latitude in the tropics. The analysis is done for $2.5^{\circ}$ latitude-longitude boxes with at least two gauges. 


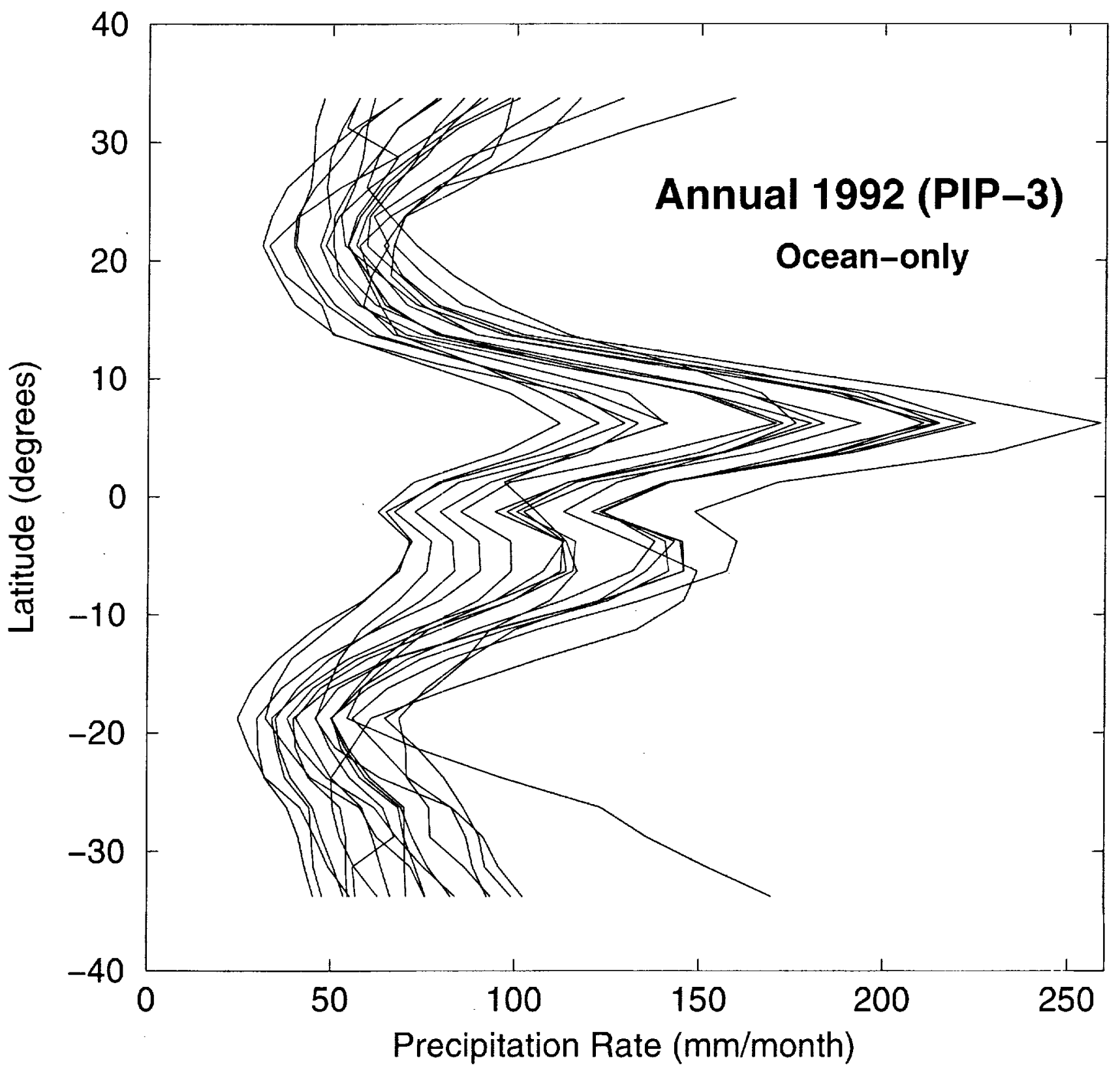



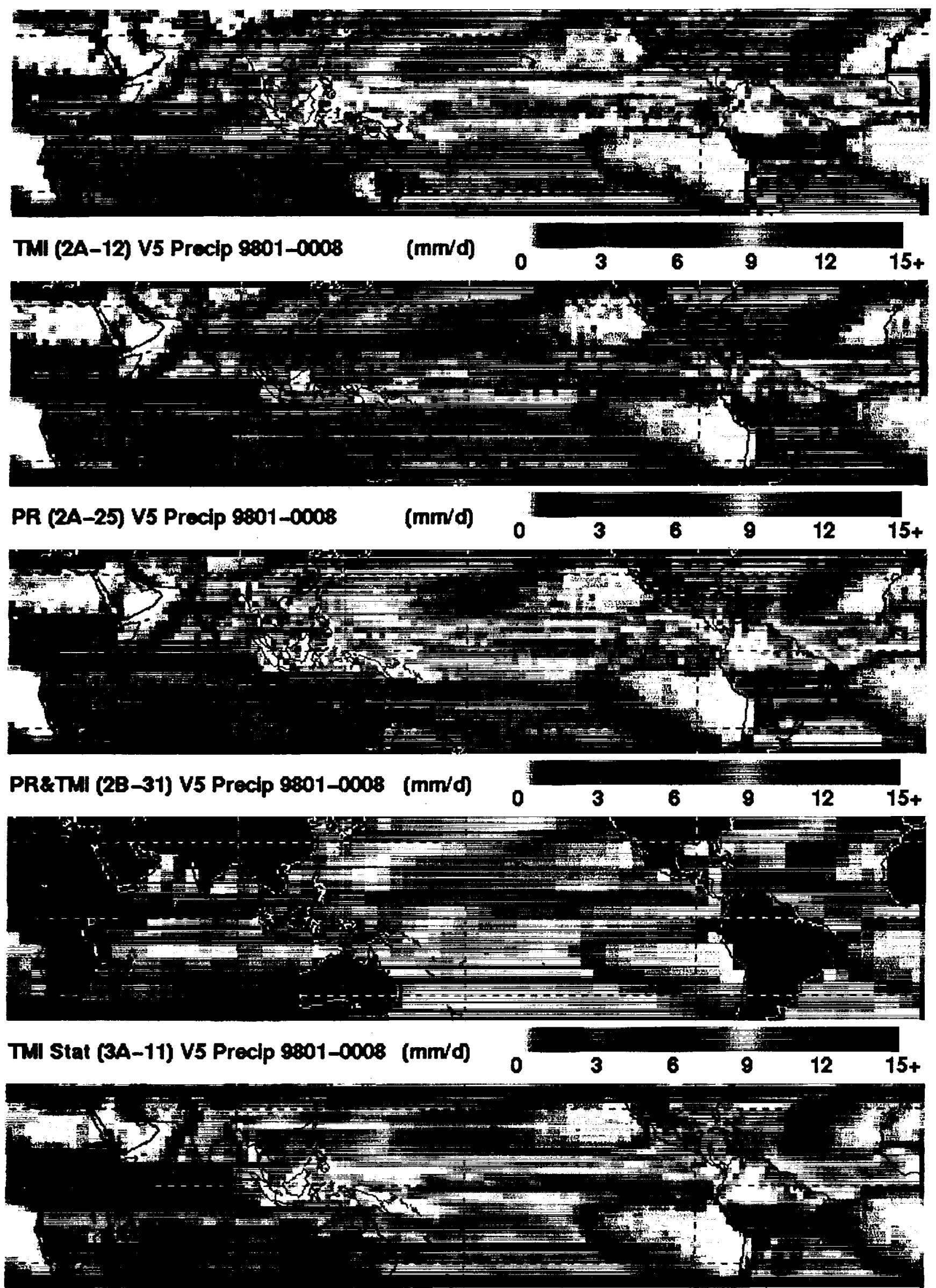


\section{TRMM V5 Zonal Mean Rainfall}
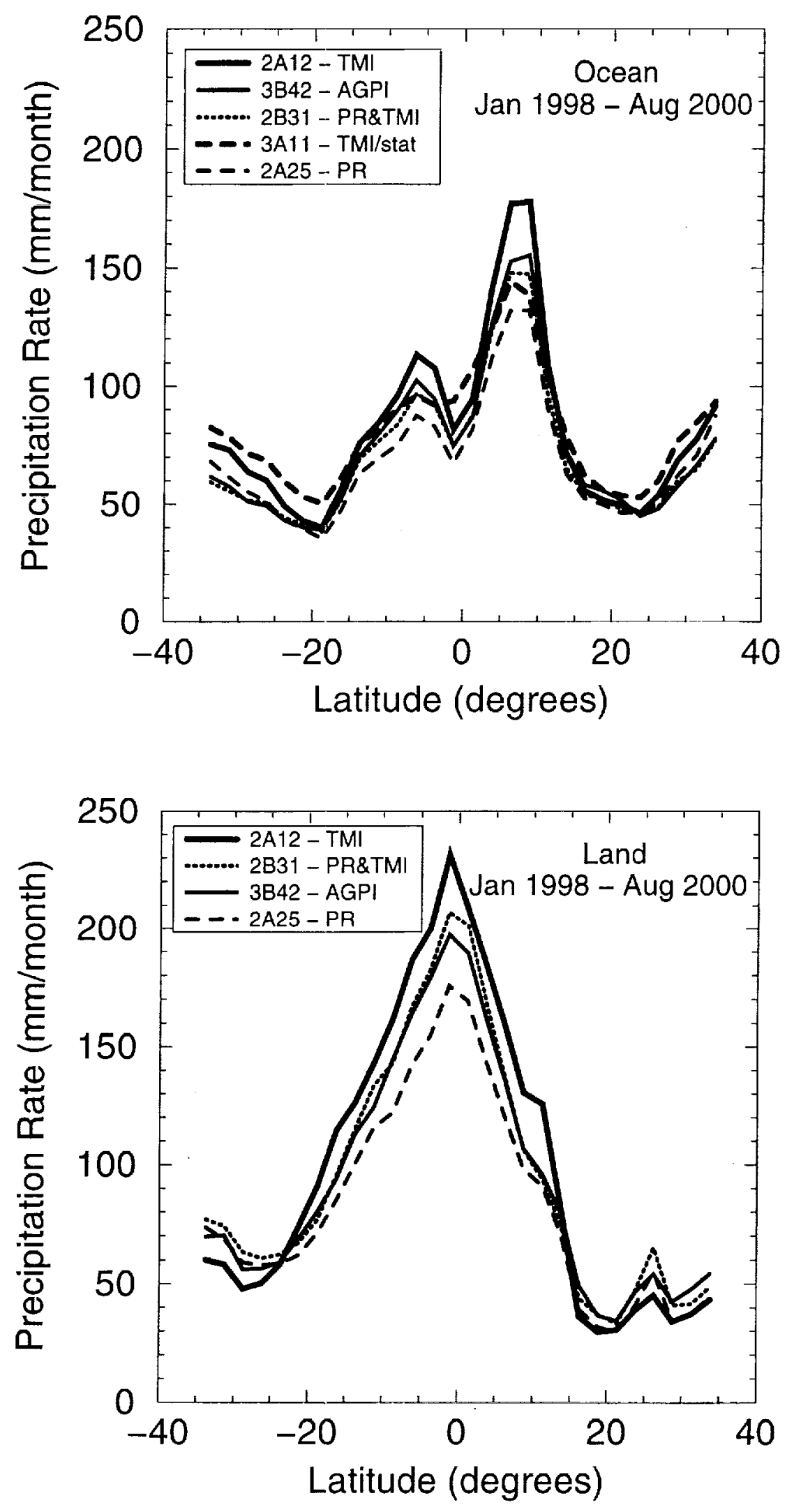
Standard Deviations

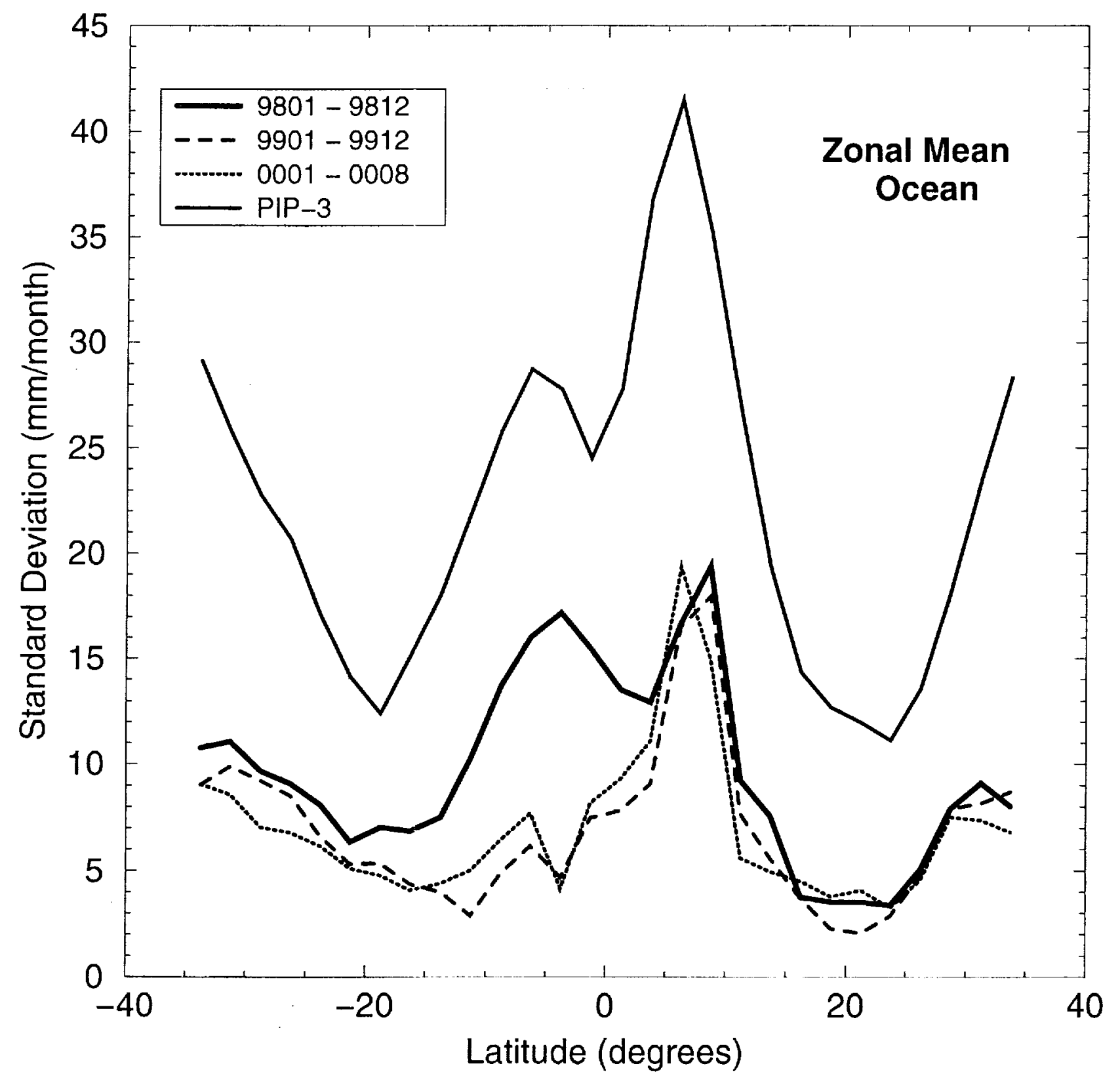




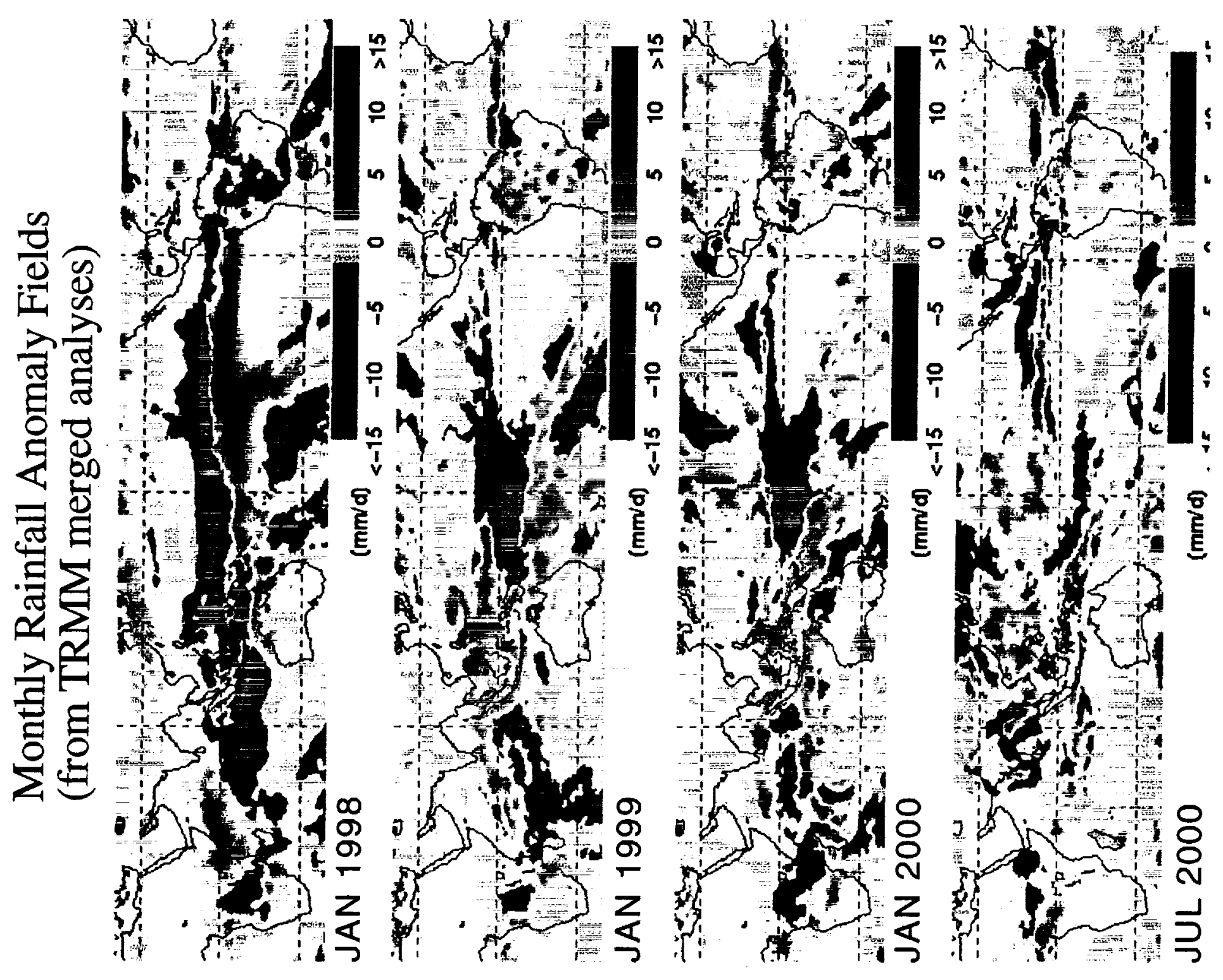


8

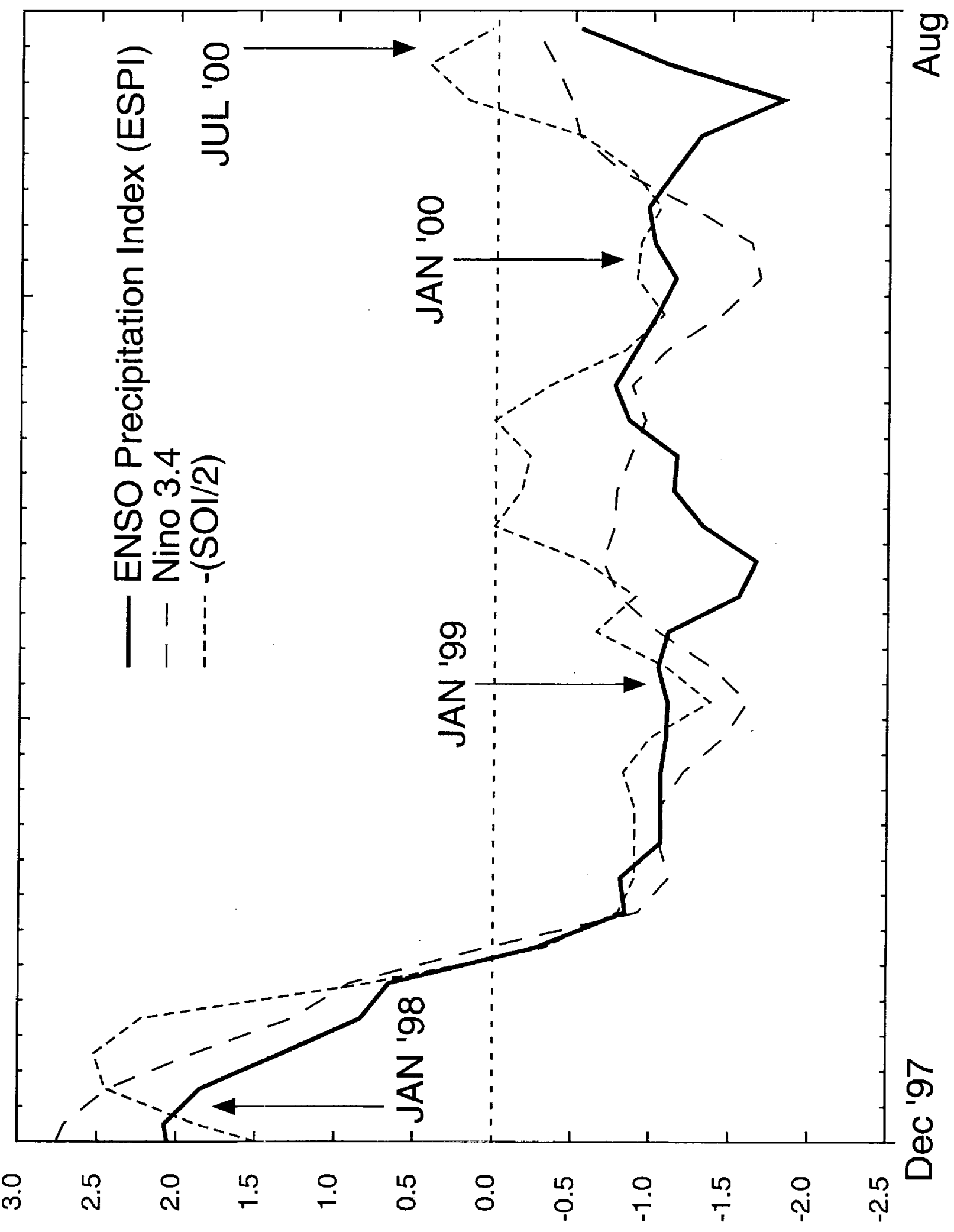


3ON-30S OCEANS
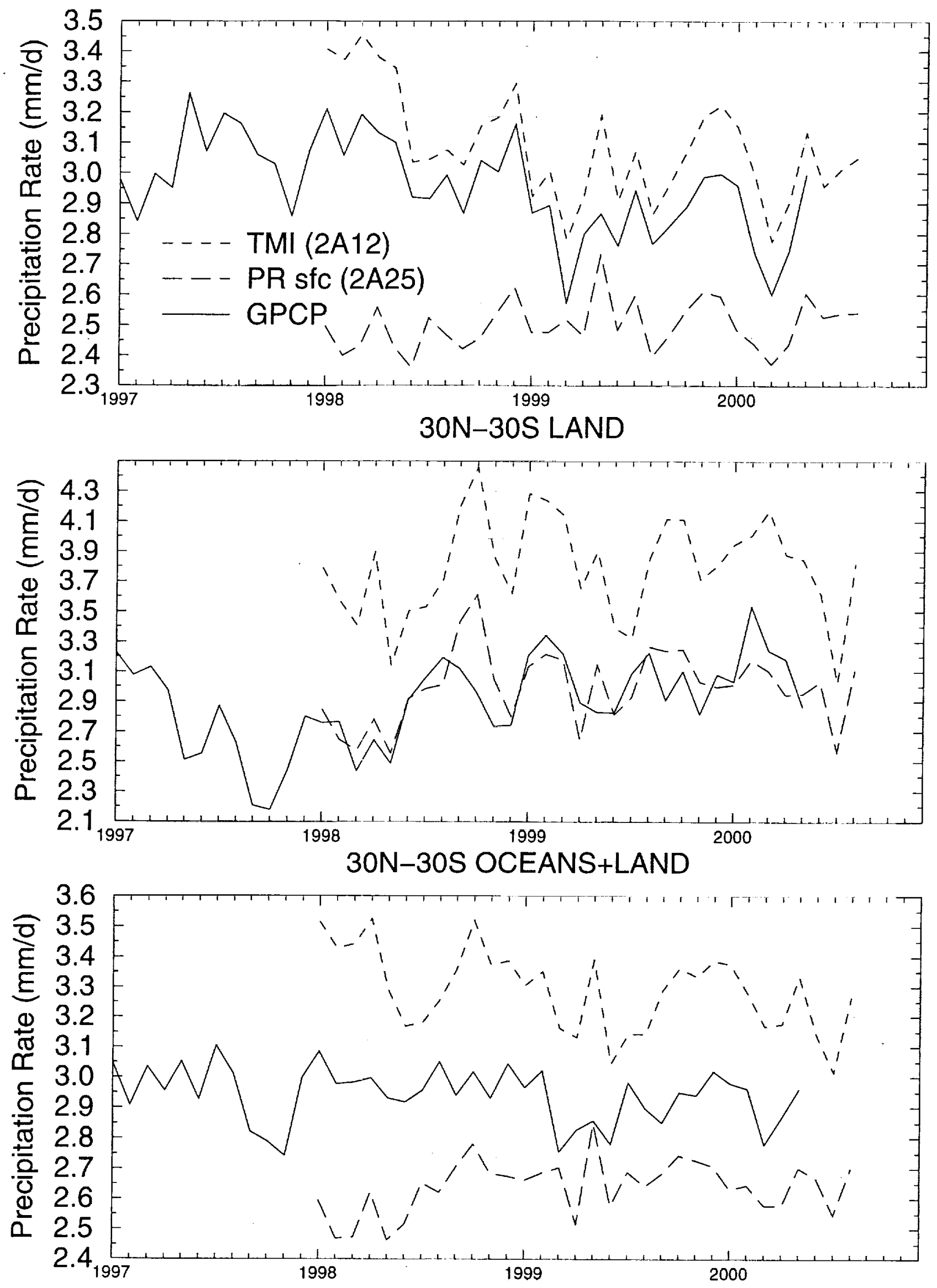


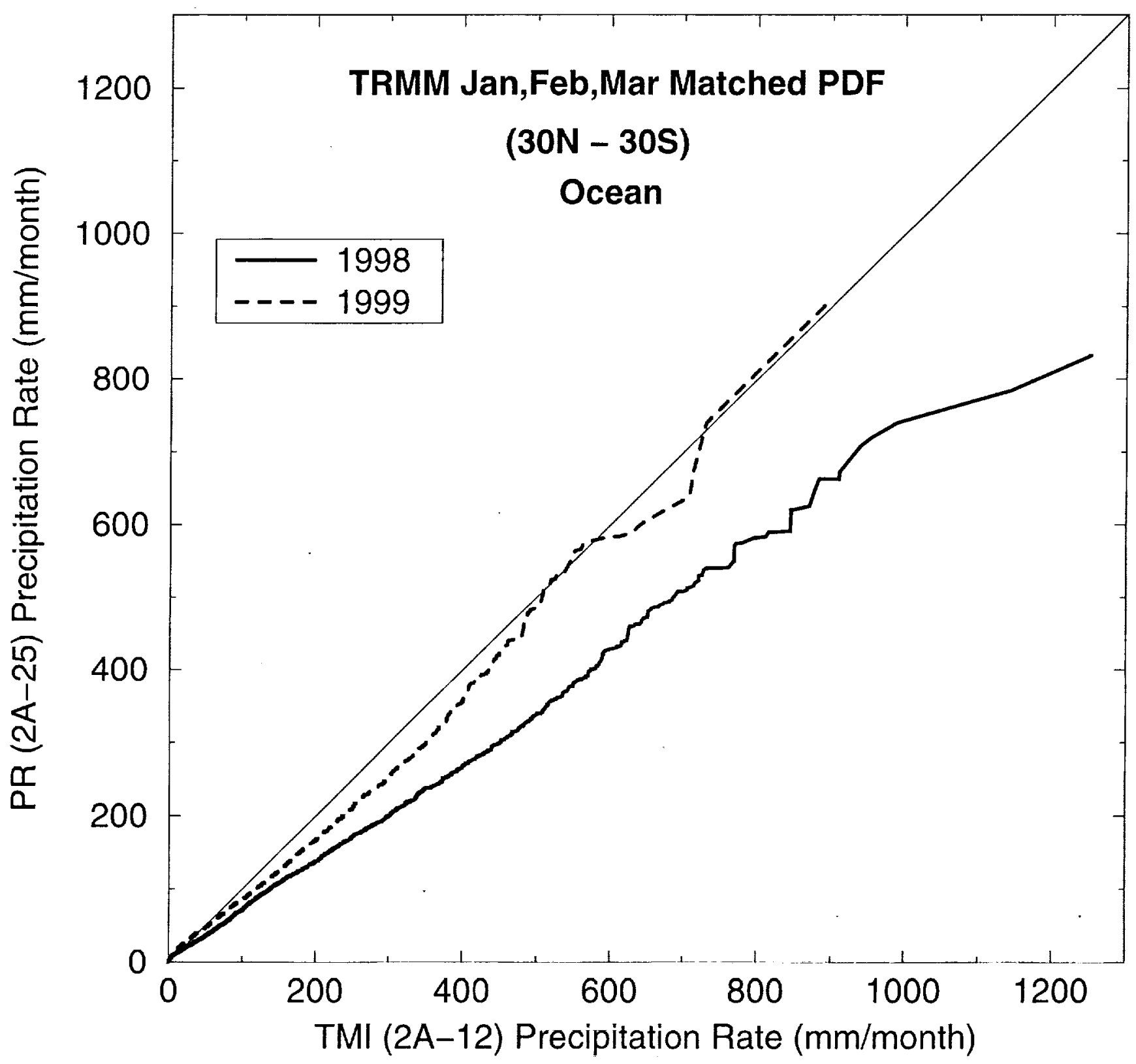




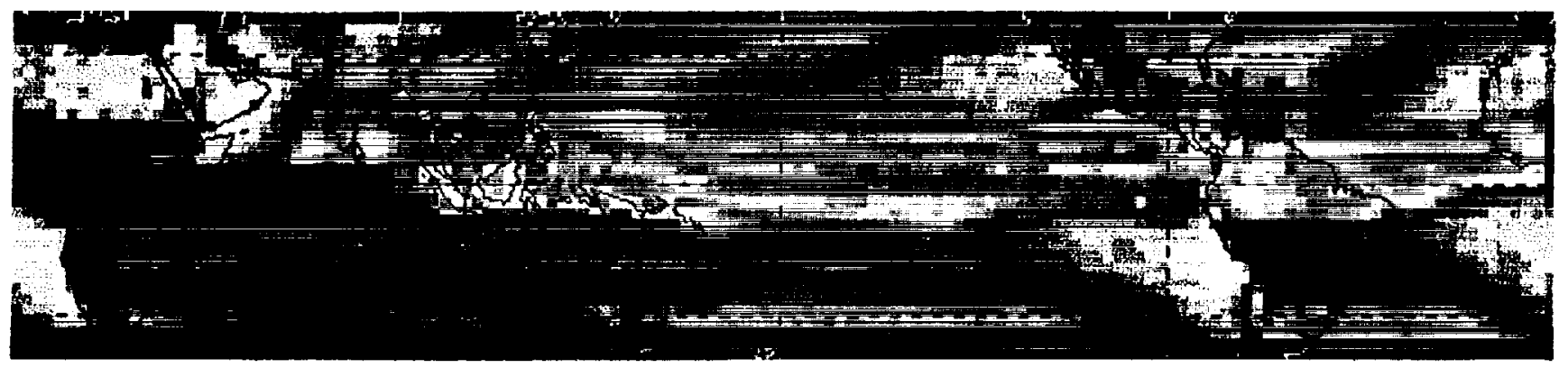

TRMM Avg Precip $\$ 801-0008$

$(\mathrm{mm} / \mathrm{d})$

0

3

6

9

12

$15+$

Fy mas

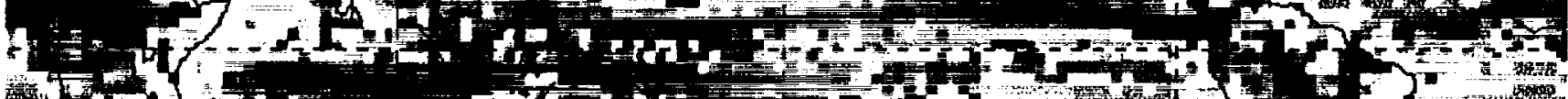

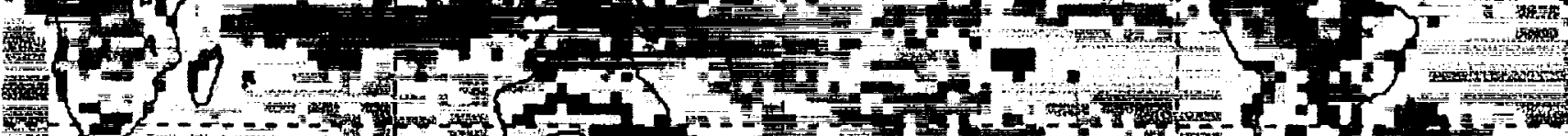

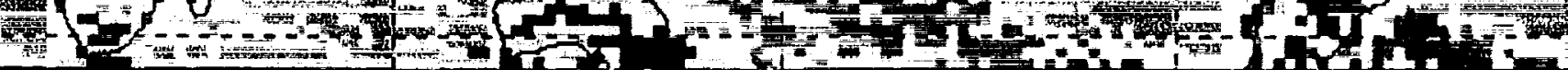
-

2A-12 - TRMM Avg $\quad(\mathrm{mm} / \mathrm{d}) \quad \begin{array}{ccccccc}<-3 & -2 & -1 & 0 & 1 & 2 & >3\end{array}$

2A-25-TRMM Avg

- Sny

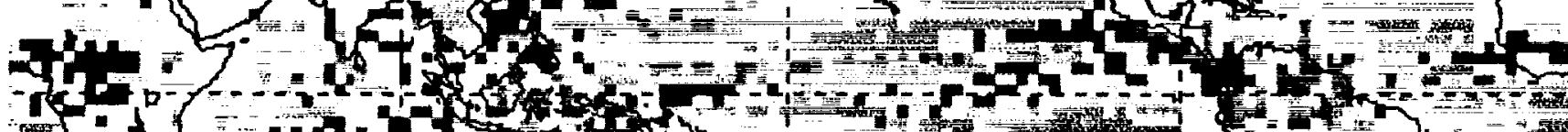

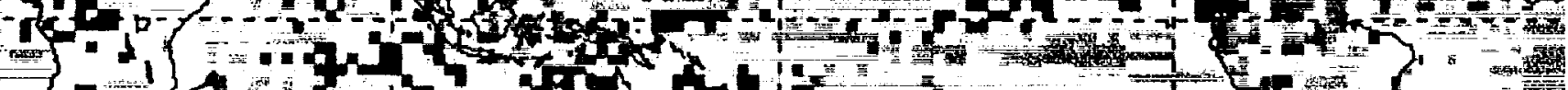
$=2-1$ of

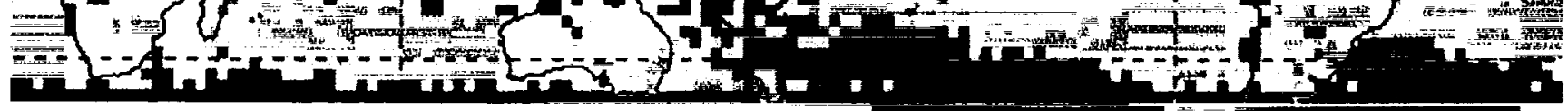
2B-31 - TRMM Avg $(\mathrm{mm} / \mathrm{d})$ 咅

$$
\begin{array}{ccccccc}
<-3 & -2 & -1 & 0 & 1 & 2 & >3
\end{array}
$$

sing

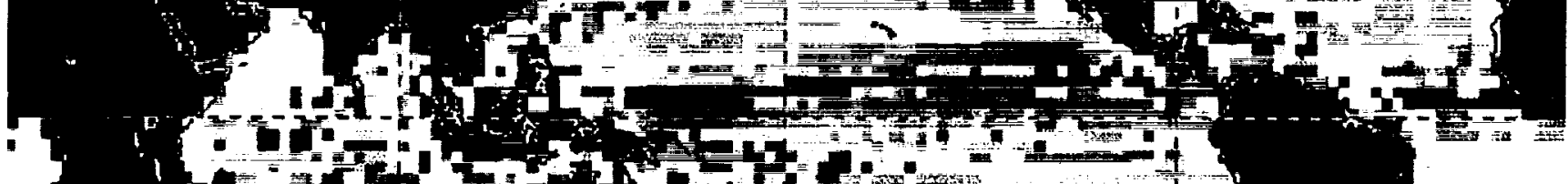

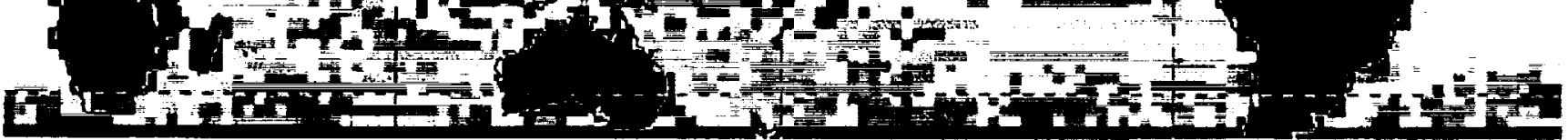
3A-11 - TRMM Avg

$(\mathrm{mm} / \mathrm{d})$ $<-3 \quad-2 \quad-1 \quad 0$ 政 $\begin{array}{llll}0 & 1 & 2 & >3\end{array}$ 


\section{TRMM vs. Pacific Atoll Gauges}

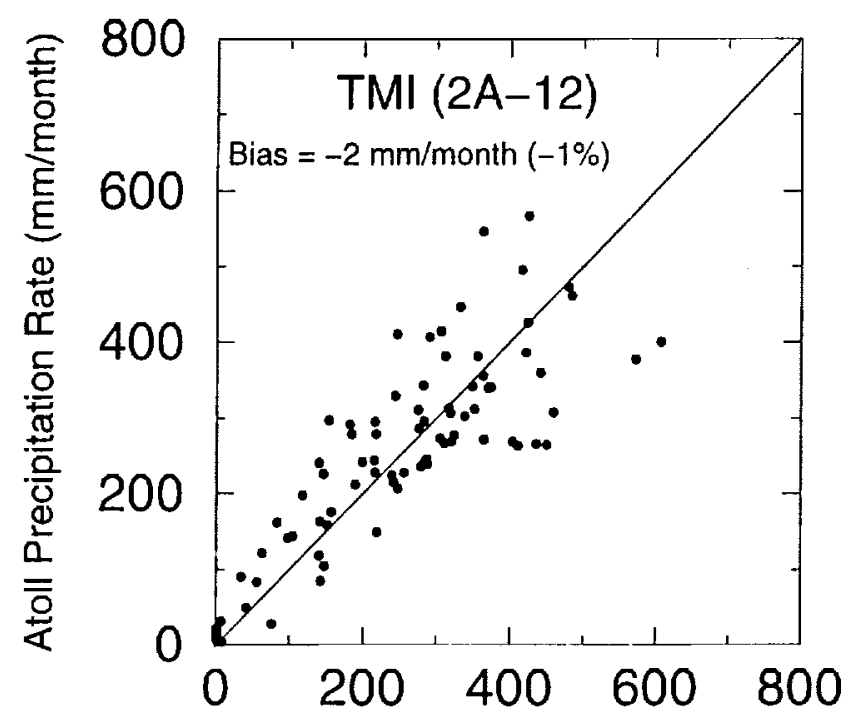

TMI (2A-12) Precipitation Rate ( $\mathrm{mm} / \mathrm{month})$

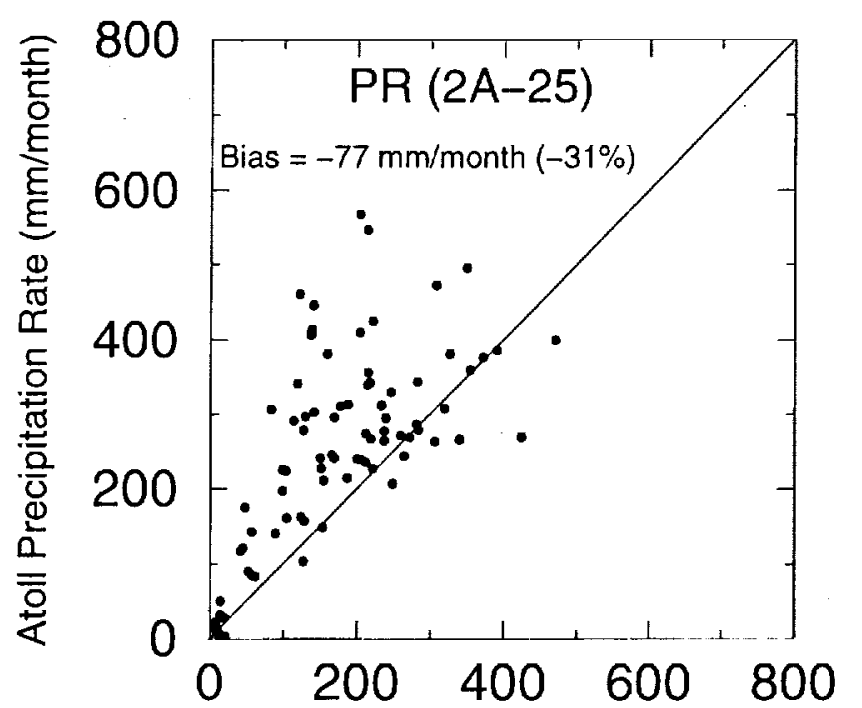

PR (2A-25) Precipitation Rate ( $\mathrm{mm} / \mathrm{month})$

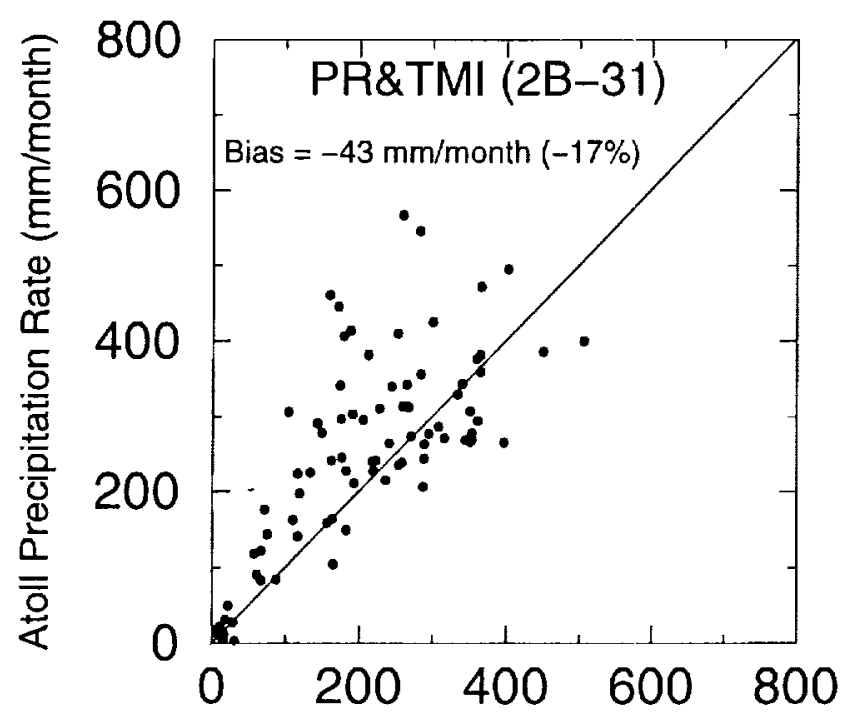

PR\&TMI (2B-31) Precipitation Rate ( $\mathrm{mm} /$ month)
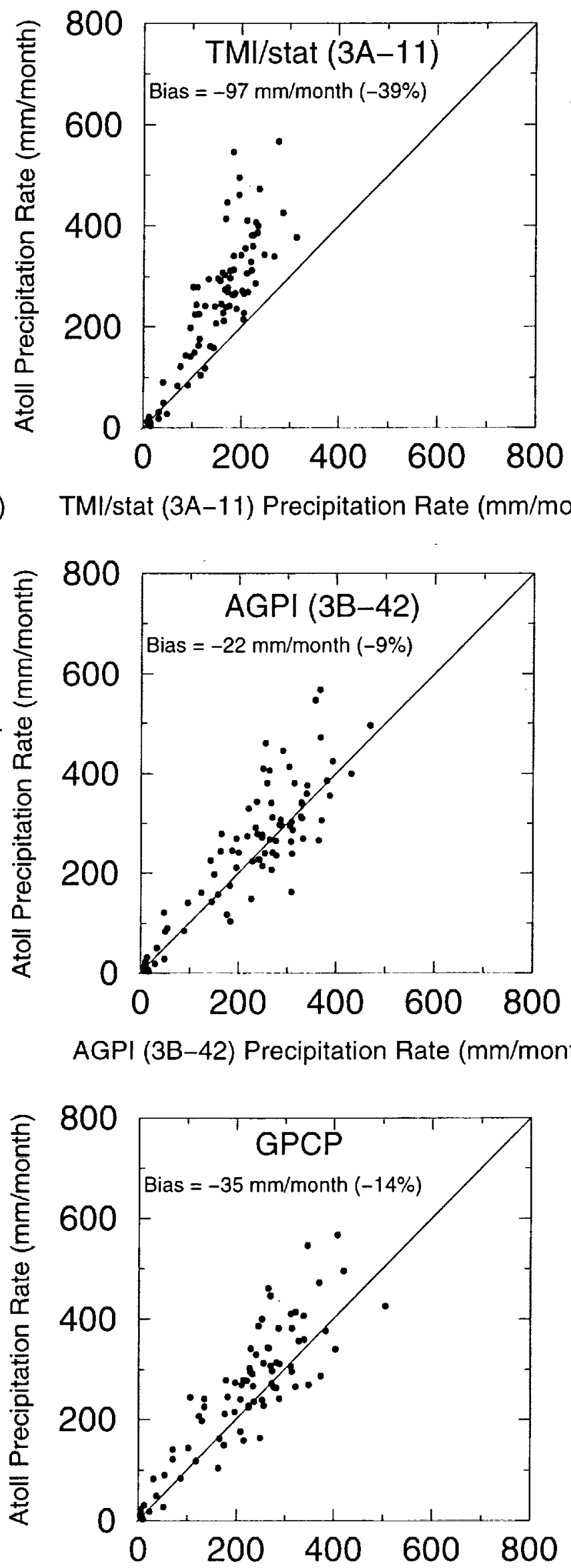

TMl/stat (3A-11) Precipitation Rate ( $\mathrm{mm} /$ month)

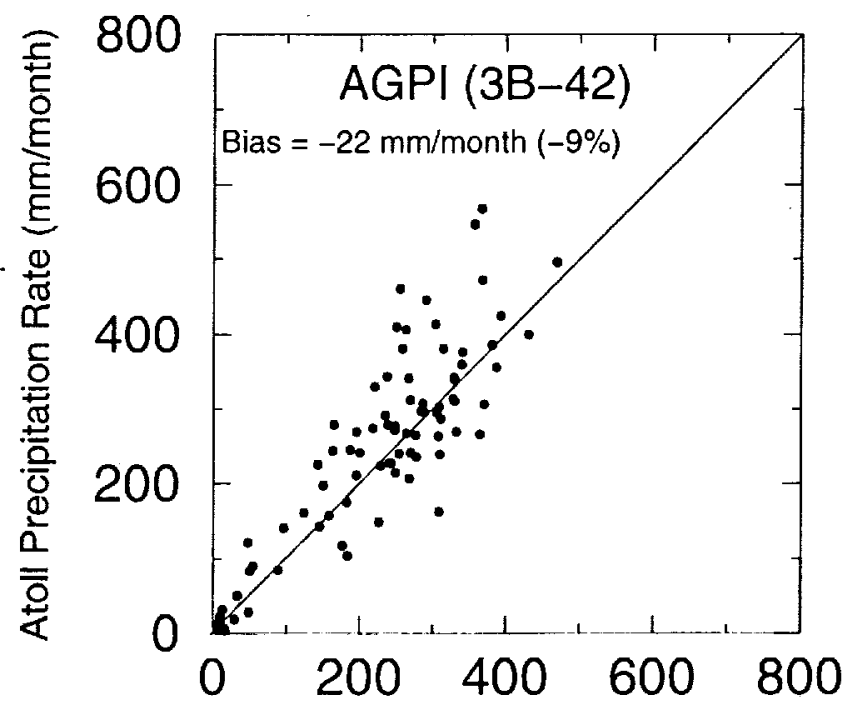

AGPI (3B-42) Precipitation Rate ( $\mathrm{mm} / \mathrm{month}$ )

GPCP Precipitation Rate ( $\mathrm{mm} / \mathrm{month}$ ) 


\section{TRMM vs. GPCC Gauges (15N-15S)}

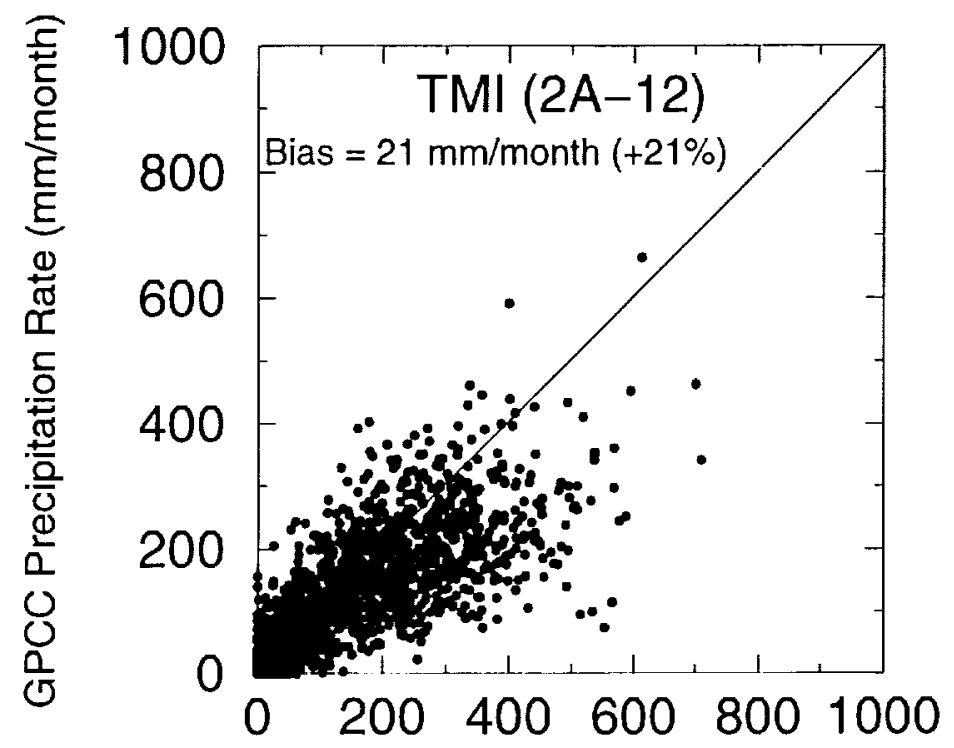

TMI (2A-12) Precipitation Rate ( $\mathrm{mm} / \mathrm{month})$

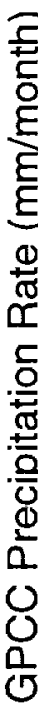

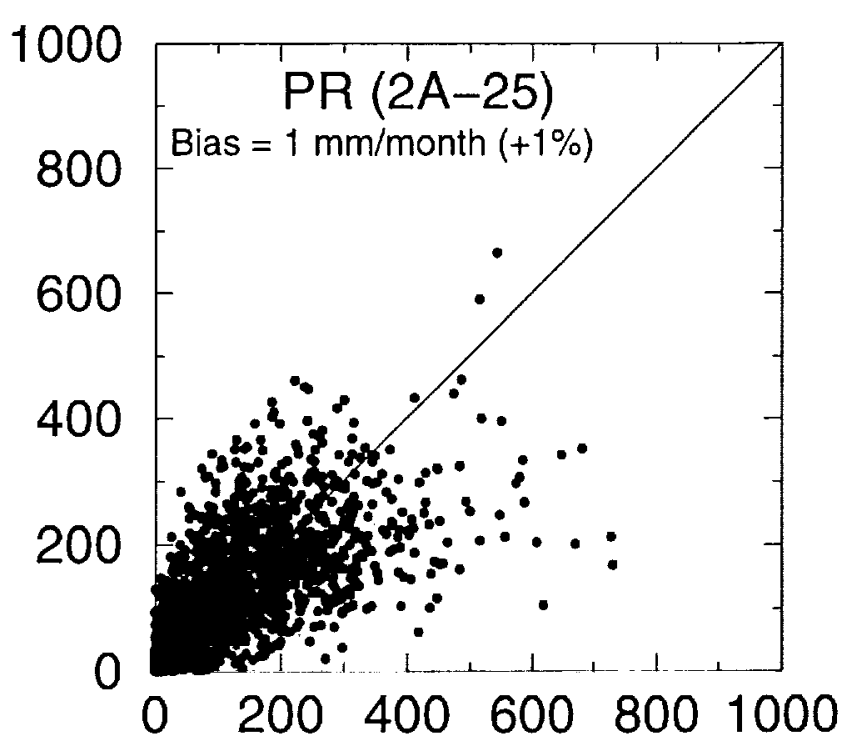

PR (2A-25) Precipitation Rate ( $\mathrm{mm} / \mathrm{month}$ )

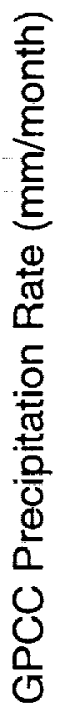

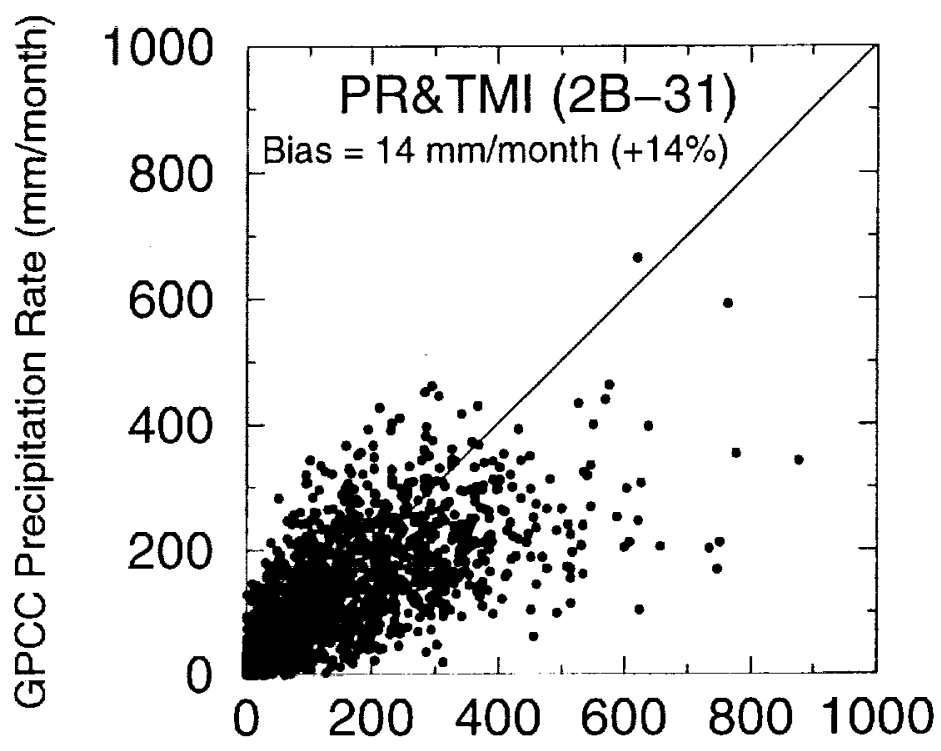

PR\&TMI (2B-31) Precpitation Rate $(\mathrm{mm} / \mathrm{mont}$

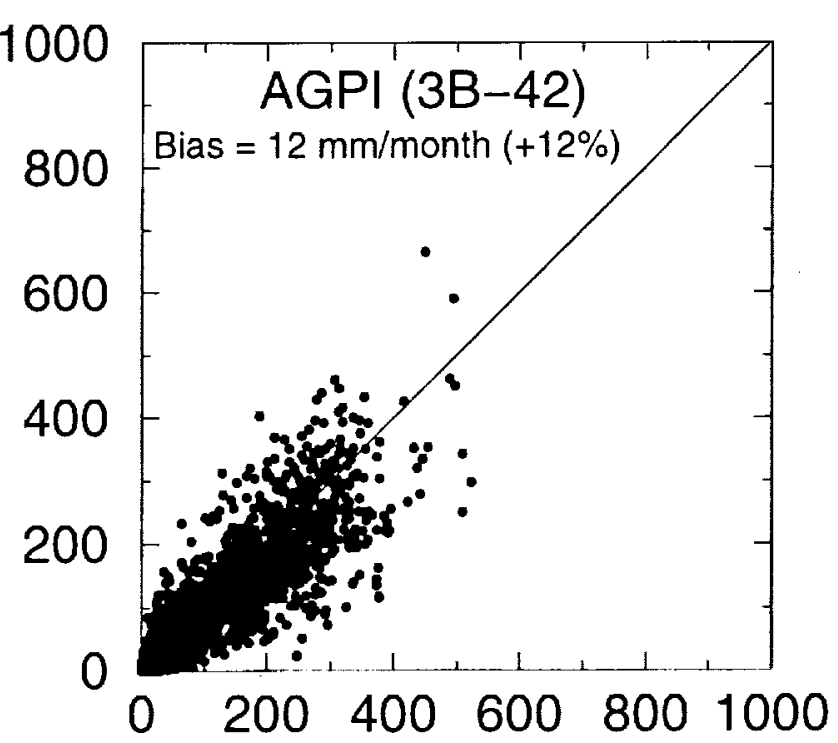

AGPI (3B-42) Precipitation Rate $(\mathrm{mm} / \mathrm{month}$ 


\section{TRMM vs. GPCC Gauges (>15NS)}

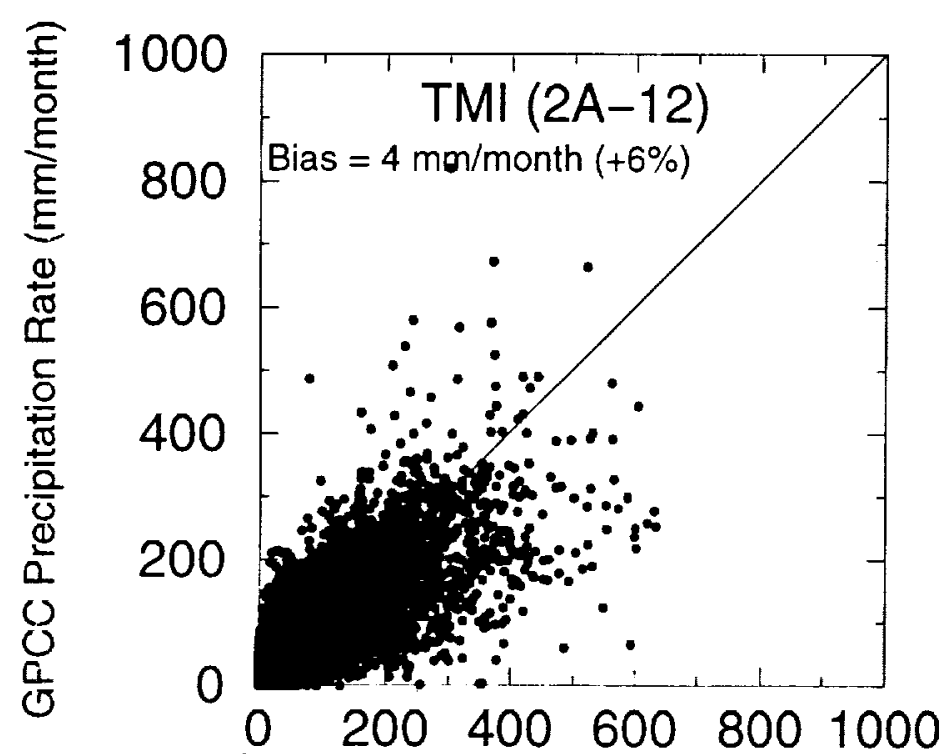

TMI (2A-12) Precipitation Rate ( $\mathrm{mm} / \mathrm{month})$
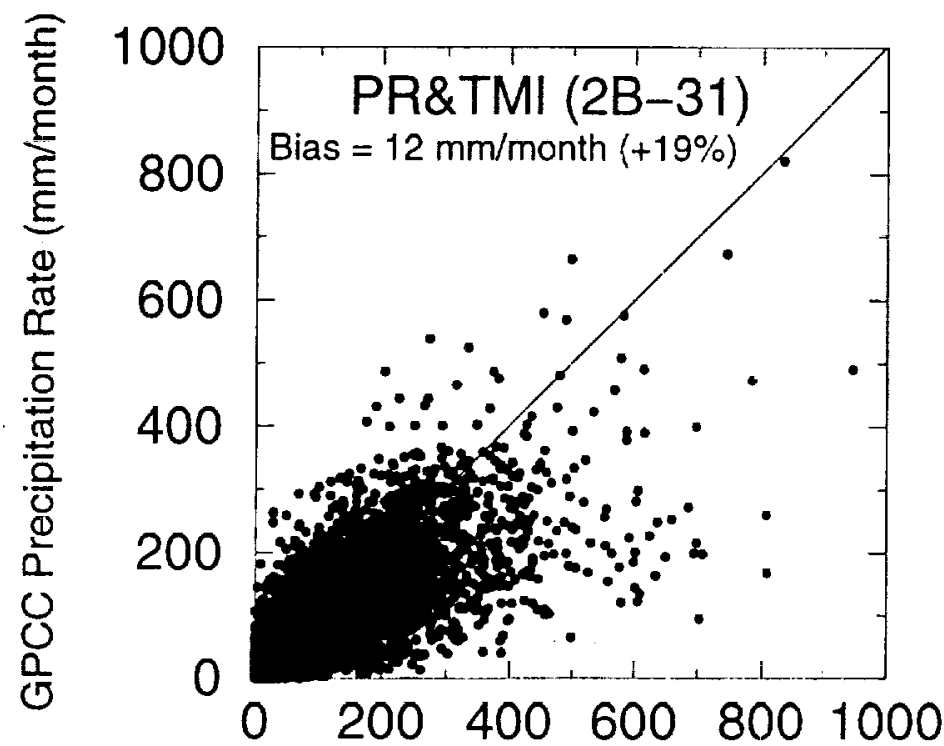

PR\&TMI (2B-31) Precpitation Rate $(\mathrm{mm} / \mathrm{month}$

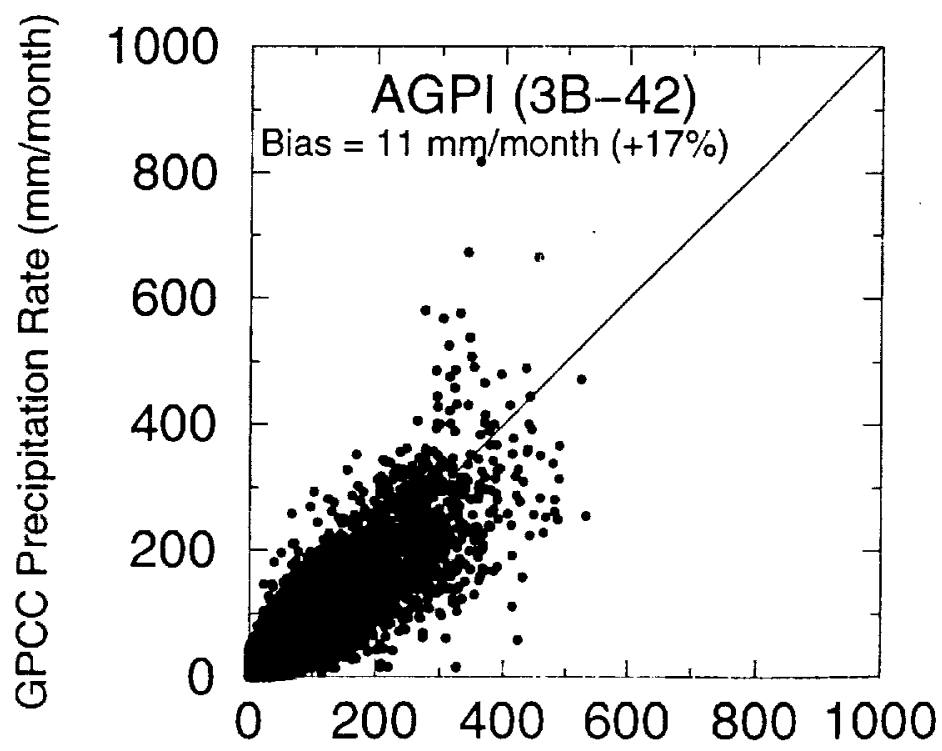

AGPI (3B-42) Precipitation Rate ( $\mathrm{mm} / \mathrm{month}$ ) 